
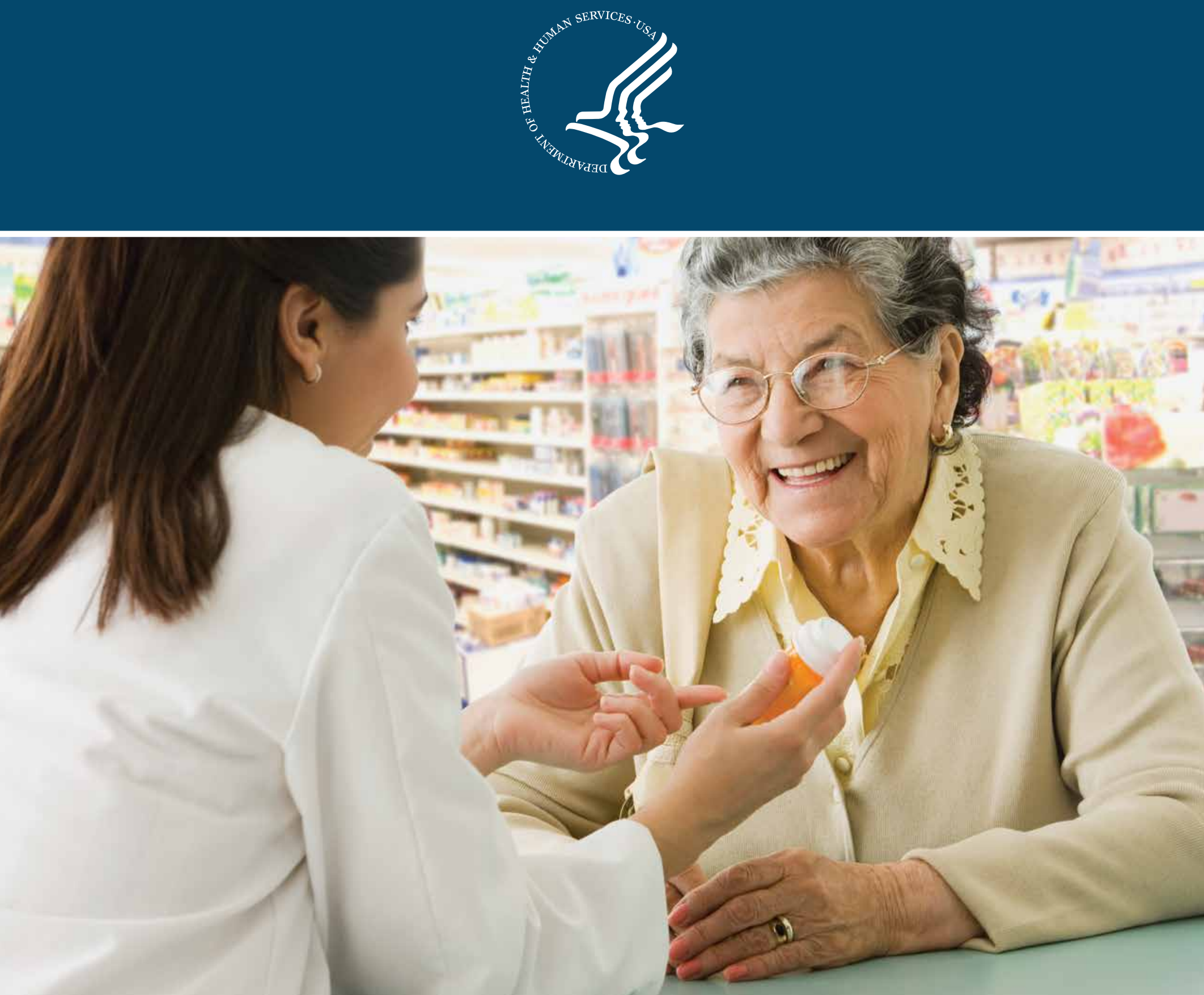
The U.S. Department of Health \& Human Services Hubert H. Humphrey Building 200 Independence Avenue, S.W. Washington, D.C. 20201

Toll Free Call Center: 1-877-696-6775 


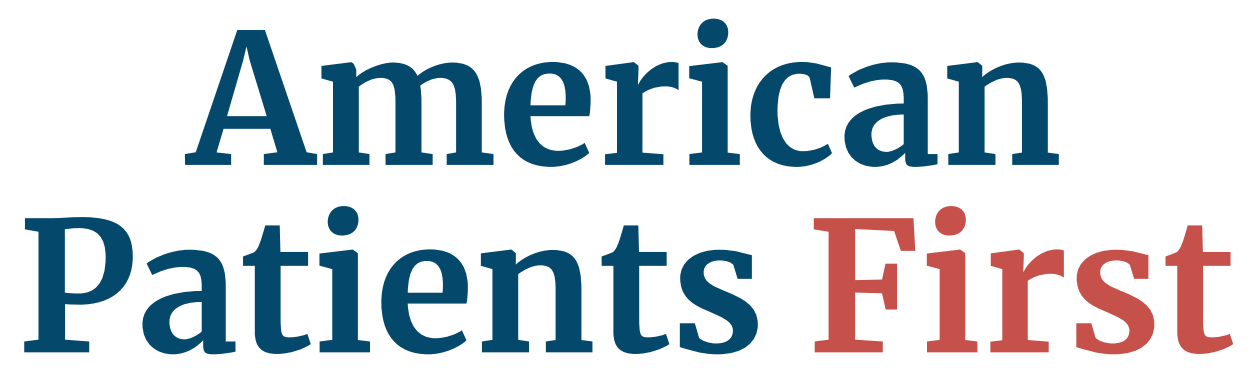

The Trump Administration Blueprint to Lower Drug Prices and Reduce Out-of-Pocket Costs

MAY 2018 

One of my greatest priorities is to reduce the price of prescription drugs. In many other countries, these drugs cost far less than what we pay in the United States. That is why I have directed my Administration to make fixing the injustice of high drug prices one of our top priorities. Prices will come down." 

The Secretary of Health and Human Services

WASHINGTON, D.C. 20201

\section{Message from the Secretary}

THE UNITED STATES is first in the world in biopharmaceutical investment and innovation. Combining our free market system and generous public investment made America home to the first chemotherapy treatments for cancer, the first effective treatments for HIV, the first cure for Hepatitis $\mathrm{C}$, and now, the first therapies that turn our own immune systems against cancer.

But too often, this system has not put American patients first. We have access to the greatest medicines in the world, but access is meaningless without affordability.

When it comes to the cost of prescription drugs, our healthcare system faces four major challenges: high list prices for drugs; seniors and government programs overpaying for drugs due to lack of the latest negotiation tools; high and rising out-ofpocket costs for consumers; and foreign governments free-riding off of American investment in innovation.
These problems have often been discussed, but gone unaddressed. Under President Trump, that has now changed. This blueprint is a historic plan for bringing down the high price of drugs and reducing out-of-pocket costs for the American consumer.

The time to act is now: Not only are costs spiraling out of control, but the scientific landscape is changing as well. Securing the next generation of cures for the next generation of American patients will require radical reforms to how our system works. Our blueprint will bring immediate relief to American patients while also delivering long-term reforms.

The men and women of the Department of Health and Human Services (HHS) are looking at every facet of HHS's programs, authorities, and spending. Working with our partners in the private sector, we will turn this vision into action, and thereby improve the health and well-being of every American.

Alex M. Azar II 



\section{CONTENTS}

I. Trump Administration Blueprint in Brief....................................................... 9

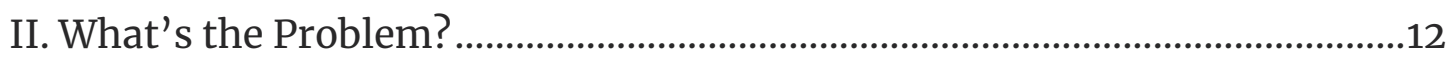

III. Trump Administration Accomplishments on Drug Pricing .........................18

IV. Responding to President Trump's Call to Action ........................................... 23

V. Further Actions Under Review and Opportunities for Feedback..................26 



\section{Trump Administration Blueprint in Brief}

HHS has identified four challenges in the American drug market:

- High list prices for drugs

- Seniors and government programs overpaying for drugs due to lack of the latest negotiation tools

- High and rising out-of-pocket costs for consumers

- Foreign governments free-riding off of American investment in innovation

Under President Trump, HHS has proposed a comprehensive blueprint for addressing these challenges, identifying four key strategies for reform:

- Improved competition

- Better negotiation

- Incentives for lower list prices

- Lowering out-of-pocket costs

HHS's blueprint encompasses two phases: 1) actions the President may direct HHS to take immediately and 2) actions HHS is actively considering, on which feedback is being solicited. 


\section{Increased Competition}

\section{Immediate Actions}

- Steps to prevent manufacturer gaming of regulatory processes such as Risk Evaluation and Mitigation Strategies (REMS)

- Measures to promote innovation and competition for biologics

- Developing proposals to stop Medicaid and Affordable Care Act programs from raising prices in the private market

\section{Further Opportunities}

- Considering how to encourage sharing of samples needed for generic drug development

- Additional efforts to promote the use of biosimilars

\section{Better Negotiation}

\section{Immediate Actions}

- Experimenting with value-based purchasing in federal programs

- Allowing more substitution in Medicare Part D to address price increases for singlesource generics

- Reforming Medicare Part D to give plan sponsors significantly more power when negotiating with manufacturers
- Sending a report to the President on whether lower prices on some Medicare Part B drugs could be negotiated for by Part D plans

- Leveraging the Competitive Acquisition Program in Part B.

- Working across the Administration to assess the problem of foreign free-riding

\section{Further Opportunities}

- Considering further use of value-based purchasing in federal programs, including indication-based pricing and long-term financing

- Removing government impediments to value-based purchasing by private payers

- Requiring site neutrality in payment

- Evaluating the accuracy and usefulness of current national drug spending data 


\section{Incentives for Lower}

\section{List Prices}

\section{Immediate Actions}

- FDA evaluation of requiring manufacturers to include list prices in advertising

- Updating Medicare's drug-pricing dashboard to make price increases and generic competition more transparent

\section{Further Opportunities}

- Measures to restrict the use of rebates, including revisiting the safe harbor under the AntiKickback statute for drug rebates

- Additional reforms to the rebating system

- Using incentives to discourage manufacturer price increases for drugs used in Part B and Part D

- Considering fiduciary status for Pharmacy Benefit Managers (PBMs)

- Reforms to the Medicaid Drug Rebate Program

- Reforms to the $340 \mathrm{~B}$ drug discount program

- Considering changes to HHS regulations regarding drug copay discount cards

\section{Lowering Out-of-Pocket Costs}

\section{Immediate Actions}

- Prohibiting Part D contracts from preventing pharmacists telling patients when they could pay less out-of-pocket by not using insurance

- Improving the usefulness of the Part D Explanation of Benefits statement by including information about drug price increases and lower cost alternatives

\section{Further Opportunities}

- More measures to inform Medicare Parts B and D beneficiaries about lowercost alternatives

- Providing better annual, or more frequent, information on costs to Part D beneficiaries 


\section{What's the Problem?}

TODAY'S COMPLEX U.S. PHARMACEUTICAL MARKET is characterized by high and rising list prices, increasing consumer out-of-pocket costs, and a new era of high-cost drugs lacking competition. Recent developments and challenges in the market include a business model built on opaque rebates and discounts that favor high list prices, a generational loss of patent exclusivity, the Affordable Care Act's taxes, rebates, and expansion of the $340 \mathrm{~B}$ drug discount program, expansion of international price controls, government programs lacking modern negotiation tools, and changes in insurance benefit design that shifted the burden of rising prices to consumers.

\section{i. A Recent Drug Pricing History}

\section{A Business Model Is Born}

Thirty years ago, the majority of prescriptions filled at retail pharmacies were cash transactions. Over time, however, health plans began to offer drug coverage to compete for new members, knowing the benefit could be offered at relatively low cost.

But the complexity, price, and benefits associated with prescription drugs dramatically increased during the 1990s. U.S. drug spending grew between 11 and $17 \%$ per year in the 1990s, as both prices and volume soared. ${ }^{1}$

As more complex and more expensive drugs came on the market,

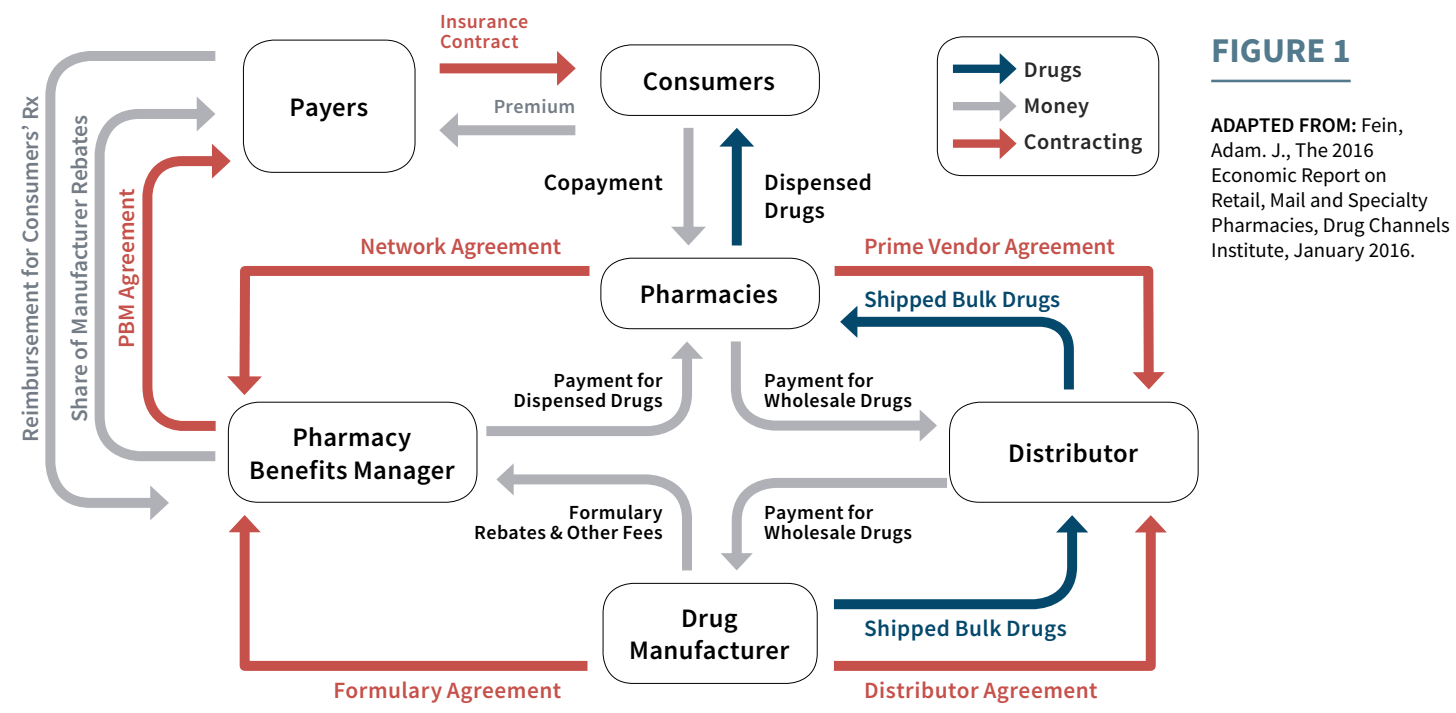




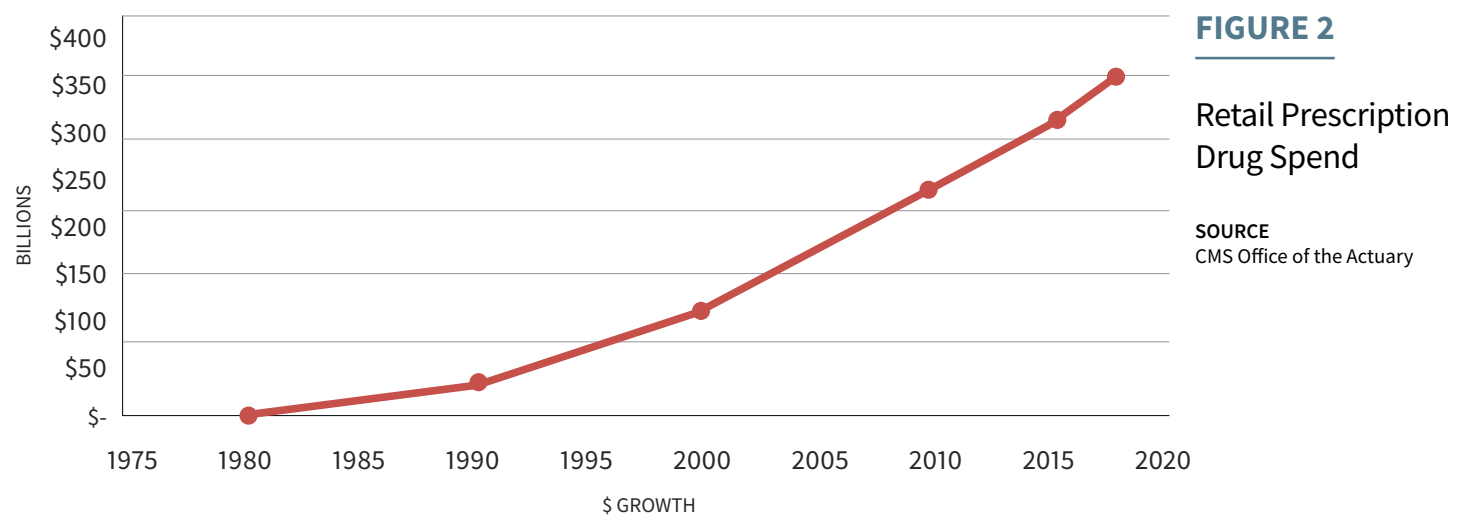

plans used formularies and copayments to manage utilization and keep drug costs low. But drug manufacturers paid rebates and discounts to be offered as preferred drugs with lower copays, and few drugs were excluded from coverage.

In response to rising prices, private health plans began to use closed formularies to manage drug spending and negotiate higher rebates and discounts from drug manufacturers, holding down increases in net drug prices.

\section{Medicare and Medicaid Evolve}

Medicare Part D introduced new dynamics to the market, as the first truly insured prescription drug benefit. Part D plan sponsors agreed to accept the financial risk of providing covered drugs to Medicare beneficiaries in exchange for a per-beneficiary, per-month payment.

Part D Plans negotiated aggressively to keep premiums and drug costs low for cost-conscious Medicare beneficiaries, and the Part D Plan Finder brought transparency to premiums, formularies, and drug prices. Private health plans outside of Medicare adopted the tools used by Part D plans, and Part D has in large part succeeded at holding down costs for seniors.

Meanwhile, drug spending has been held down in the Medicaid program by other tools. The program's rules prohibit the use of closed formularies, but states use "preferred drug lists" to negotiate larger supplemental rebates than required by law and limit the use of drugs made by manufacturers not offering supplemental rebates. As a result, drug manufacturers have faced pressure to offer higher rebates to maintain volume, or risk losing revenue growth caused from being excluded from markets.

\section{A Generational Loss of Exclusivity}

Around two decades after the boom in drug spending of the 1990s, beginning in 2012, the expiration of patents of popular drugs - many "blockbuster drugs" with U.S. sales 
of $\$ 1$ billion or more-led to the loss of over $\$ 140$ billion in drug manufacturer revenue. ${ }^{2}$ New generic competition coincided with a slowdown in new product development, creating additional financial pressure.

\section{Affordable Care Act Taxes and Rebates}

The Affordable Care Act (ACA) shifted costs and changed the Medicaid Drug Rebate Program in ways that may have driven up prices for consumers, especially in the private market.

The ACA also created a new tax on branded prescription drug sales to Medicare, Medicaid, and other government health care programs. Drug companies paid $\$ 2.5$ billion in 2011, based on their market share in government programs, a number that increased to \$4.1 billion in 2018 . The ACA also increased the mandatory Medicaid base rebate on brand name drugs to $23.1 \%$, and extended the Medicaid rebate to drugs purchased by Medicaid Managed Care Organizations, more than doubling the number of Medicaid covered lives using rebate-eligible drugs. ${ }^{3,4}$ This expansion of discounts may have placed pressure on list prices by forcing drug manufacturers to raise prices overall.

\section{B Growth}

The ACA also increased the demands on the $340 \mathrm{~B}$ drug discount program: For one, it made critical access hospitals and other hospital types el- igible for the first time, while the ACA's Medicaid expansion made more hospitals eligible by increasing their Disproportionate Share Hospital enrollment. ${ }^{5}$

In fact, the number of $340 \mathrm{~B}$ hospitals grew from nearly 1,700 in 2011 to 2,479 in 2017 . The number of non-hospital covered entities, offsite clinics or "child sites," hospital outpatient departments, and contract pharmacies also grew substantially. ${ }^{6}$ As a result, discounted drug purchases made by covered entities under the $340 \mathrm{~B}$ program totaled more than $\$ 16$ billion in 2016nearly a $400 \%$ increase in purchases from 2009.7 The additional billions of dollars in discounted sales and the cross-subsidization necessary may have created additional pressure on manufacturers to increase list price.

\section{Growth in International Price Controls}

The global financial crisis in 2008 spurred austerity measures in most European countries, including more aggressive use of existing drug price controls. Between 2010 and 2011, 23 countries implemented 89 distinct measures to contain government spending on prescription drugs. Most used their single-payer healthcare systems to impose drug price controls alongside increased copayments, value-added tax rates on prescription drugs, and other measures. ${ }^{8}$

In 2013, the World Health Organization published a paper de- 
scribing the growing use of external reference pricing, or the practice of using the price of a medicine in one or several countries to derive a benchmark or reference price for the purposes of setting or negotiating the price of the product in a given country. ${ }^{9}$ Every time one country demands a lower price, it leads to a lower reference price used by other countries. Such price controls, combined with the threat of market lockout or intellectual property infringement, prevent drug companies from charging market rates for their products, while delaying the availability of new cures to patients living in countries implementing these policies.

\section{ii. Where We Are Today}

\section{Industry Impact}

The loss of patent exclusivity on successful products, new ACA taxes, and requirements to extend higher rebates and discounts to a markedly increased Medicaid and 340B population created an estimated $\$ 200$ billion of downward pressure on pharmaceutical industry revenues-during a five-year period when innovation was decreasing. International price controls and delayed global product launches exacerbated the problem.

Absent new products to launch and the ability to increase revenue through volume, and in the face of a more sophisticated PBM industry demanding higher rebates and restricting access to markets, the in-
One in seven employees, and a growing number of people with individuallypurchased insurance, now have a separate drug deductible.

dustry turned to its remaining tool to drive growth: increasing price.

Prices soared on certain advanced small molecule drugs and new specialty drugs. Meanwhile, PBMs exploited new utilization management tools and "price protection" contracts to extract even higher rebates, further widening the gap between list and net prices.

Each increase in list prices satisfied the drug industry's need to grow revenue and increased administrative fees paid to PBMs, but also boosted the prices paid by payers and, especially, consumers.

\section{Lack of Modern Negotiation Tools in Government Programs}

Private health plans in non-govern- 


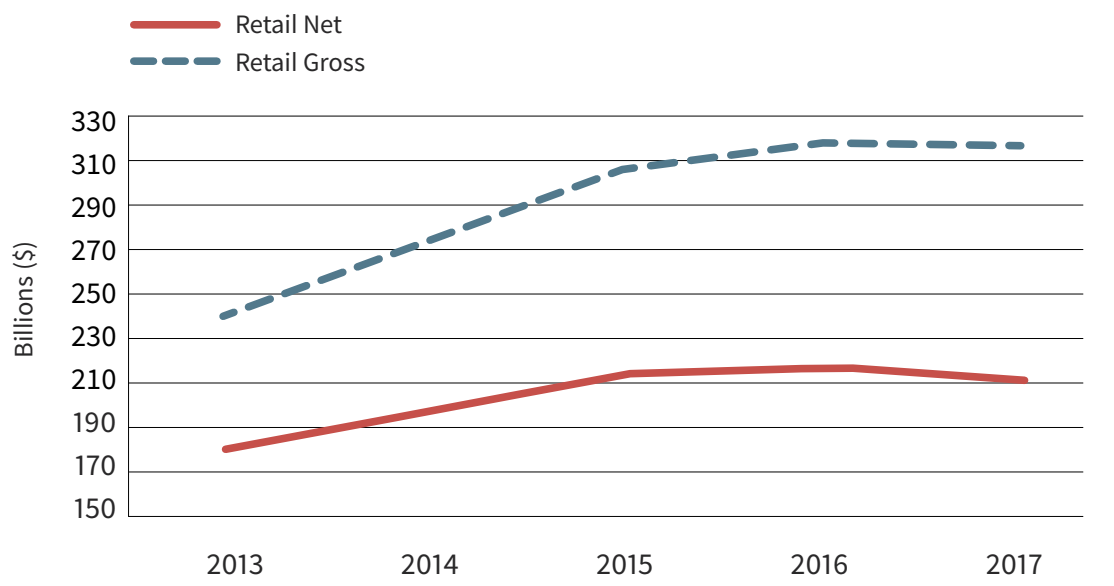

FIGURE 3

List Price vs.

Net Price

SOURCE

Medicine Use and Spending in

the U.S.; A Review of 2017 and

Outlook to 2022. April 19, 2018 ment programs use aggressive formulary management tools to negotiate better deals for high-cost drugs dispensed in pharmacies. Private health plans are also presently experimenting with competitive acquisition and utilization management of drugs administered in physicians' offices.

Medicare rules limit the ability of Part D plans to use these tools, making it harder for plans to negotiate as effectively for drugs, particular highcost drugs that lack competition.

\section{Changes in Benefit Design}

Consumers are more and more being exposed to the rising cost of their prescription drugs.

In 2016 , nearly $40 \%$ of adults with employer-sponsored insurance, and over half of adults with individually purchased insurance, enrolled in a high-deductible health plan. One in seven employees, and a growing number of people with individually-purchased insurance, now have a separate drug deductible. ${ }^{10}$ Private health plans in both the employer-sponsored and individually-purchased markets are more frequently relying on prescription drug coinsurance regardless of formulary tier, although they do so most often for non-preferred brands and specialty drugs.

Consumers who have not met their deductible or are subject to coinsurance, pay based on the pharmacy list price, which is not reduced by the substantial drug manufacturer rebates paid to PBMs and health plans. As a result, the growth in list prices, and the widening gap between list and net prices, markedly increases consumer out-of-pocket spending, particularly for high-cost drugs not subject to negotiation.

This is not only a financial challenge, but a health issue as well: One study found that consumers asked to pay $\$ 50$ or more at the pharmacy counter are four times more likely to abandon the prescription than a consumer charged $\$ 10 .^{11}$ 


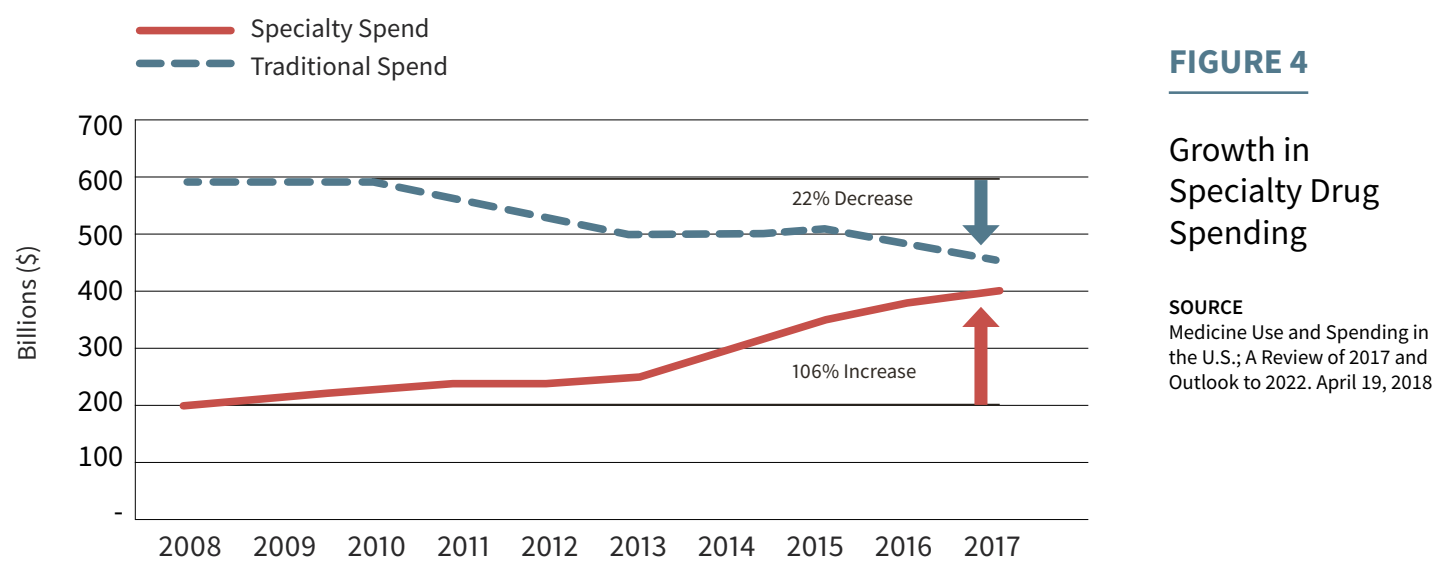

What had been a hidden negotiation and wealth transfer between drug manufacturers and PBMs is now a direct increase on consumer out-ofpocket spending that likely decreases drug adherence and health outcomes.

\section{The Growth of High-Cost Drugs}

New challenges are emerging onto this landscape. A growing number of complex drugs account for a growing percentage of health care spending. The pharmaceutical industry has shifted its attention to high-cost drugs that face little to no competition, because they offer the freedom to set high launch prices and increase them over time.

Though these drugs offer hope to the 1 percent of insured beneficiaries who use them, they account for $35-40 \%$ of health plan spending, and will increase to over half of drug spending over the next 5 years. ${ }^{12}$ Absent reform, the growth of high cost drugs will further compound the issues already described.

\section{The Situation Today}

Taken together, these drivers contribute to high and rising list prices and consumer out-of-pocket spending. Because health plans, pharmacy benefit managers (PBMs), and wholesalers receive higher rebates and fees when list prices increase, there is little incentive to control list prices. Consumers, however, pay higher copayments, coinsurance, or pre-deductible out-of-pocket costs when list prices rise.

The Trump Administration believes it is time to realign the system in four ways: increasing competition, improving government negotiation tools, creating incentives for lower list prices, and bringing down out-of-pocket costs for consumers. 


\section{Trump Administration Accomplishments on Drug Pricing}

THE PRESIDENT has consistently emphasized the need to reduce the price of prescription drugs. The Trump Administration has already taken a number of significant administrative steps, and proposed in the President's FY2019 Budget, to improve competition and end the gaming of regulatory processes, support better negotiation of drug discounts through government insurance programs, create incentives for pharmaceutical companies to lower list prices, and reduce consumer outof-pocket spending at the pharmacy and other care settings.

\section{A. Increasing Competition}

Since the beginning of the Trump Administration, HHS has taken a number of actions to increase competition and end the gaming of regulatory processes that may keep drug prices artificially inflated or hinder generic, branded, or biosimilar competition. These efforts include:

- Accelerating Food and Drug Administration (FDA) approval of generic drugs. Studies show that greater generic competition is associated with lower prices. FDA is publishing the names of drugs that have no competitors in order to spur new entrants and bring prices down. Over 1,000 generic drugs were approved in 2017, which is the most in FDA's history in a calendar year by over 200 drugs. These generic approvals saved American consumers and taxpayers nearly \$9 billion in 2017.

- Drug Competition Action Plan. In 2017, President Trump's FDA established a Drug Competition Action Plan to enable patients to access more affordable medications by focusing the agency's efforts in three key areas: (1) improving the efficiency of the generic drug development, review, and approval process; (2) maximizing scientific and regulatory clarity with respect to complex generic drugs; and (3) closing loopholes that allow brand-name drug companies to "game" FDA rules in ways that forestall the generic competition Congress intended. The agency also has taken steps to prioritize its review of generic drug applications; issued guidance to improve efficiencies in the development, review, and approval processes for generic drugs, including 
complex generic drugs; and issued guidance to further streamline the submission and review process for shared system Risk Evaluation and Mitigation Strategies (REMS), and to allow collective submissions to streamline the review of shared REMS.

- FDA also announced it will facilitate opportunities for enhanced information sharing between manufacturers, doctors, patients and insurers to improve patient access to medical products, including through value-based insurance.

- Speeding access to more affordable generics by spurring competition. Today, a generic manufacturer that has been awarded 180-day exclusivity for being the first generic to file can "park" its application with FDA, preventing additional generic manufacturers from entering the market. The President's FY2019 Budget proposes to prevent companies from using their 180day exclusivity to indefinitely delay real competition and savings for consumers by seeking a legislative change to start a company's 180-day exclusivity clock in certain instances when another generic application is ready for approval, but is blocked solely by such a first applicant's 180-day exclusivity.
- Finalizing a policy in which each biosimilar for a given biologic gets its own billing and payment code under Medicare Part B, to incentivize development of additional lower-cost biosimilars. Prior approaches to biosimilar coding and payment would have created a race to the bottom of biosimilar pricing, while leaving the branded product untouched, making it an unviable market that few would want to enter.

\section{B. Better Negotiation}

Medicare Part D has been very successful since it launched in 2006. However, prescription drug markets are different than they were 12 years ago, and in some cases Part D plan sponsors may be prohibited from doing what private payers outside the Medicare program do to negotiate effectively and keep costs low. More can also be done across the Medicare program to provide beneficiaries with the lower costs and greater price transparency resulting from better negotiation.

Since the beginning of the Trump Administration, HHS has taken a number of actions to support better negotiation. These efforts include:

- Finalizing changes to the Medicare Prescription Drug Program in the 2019 Part $C$ and Part D regulation allowing for faster mid-year substitution of generic drugs onto formularies. 
"We're the largest buyer of drugs in the world, and yet we don't bid properly."

- PRESIDENT TRUMP

- Proposing in the President's FY2019 Budget a 5-part plan to modernize the Medicare Part D program, a portion of which includes enhancing Part D plans' negotiating power with manufacturers by changing Part $D$ plan formulary standards to require a minimum of one drug per category or class rather than two. We note that the 5-part plan is intended to be implemented together, as eliminating even one piece of the package significantly changes the proposal's impacts.

- Proposing in the President's FY2019 Budget to address abusive drug pricing by manufacturers by: establishing an inflation limit for reimbursement of Medicare Part B drugs; reducing Wholesale Acquisition Cost (WAC)-Based Payment when Average Sales
Price (ASP) isn't available; and improving manufacturers' reporting of Average Sales Prices to set accurate payment rates.

- Increasing the integrity of the Medicaid Drug Rebate Program, so that manufacturers pay their fair share in rebates, by proposing in the President's FY2019 Budget to remove ambiguity regarding how drugs should be reported under the program. HHS is also manually reviewing each new drug that has been reported in the Medicaid rebate system on a quarterly basis to make sure classifications are correct, and the United States took legal action against Mylan for its misclassification of EpiPen, resulting in an agreement for Mylan to pay back $\$ 465$ million in rebate payments.

- Proposing in the President's FY2019 Budget to further clarify the Medicaid definition of brand drugs, which would address inappropriate interpretations leading some manufacturers to classify certain brand and overthe-counter drugs as generics for Medicaid rebate purposes, reducing the rebates they owe.

- Proposing in the President's FY2019 Budget to call for new Medicaid demonstration authority

i. https://www.whitehouse.gov/wp-content/uploads/2018/02/budget-fy2019.pdf 
for up to five states to test drug coverage and financing reforms that build on private sector best practices. Participating states would determine their own drug formularies, coupled with an appeals process to protect beneficiary access to noncovered drugs based on medical need, and negotiate drug prices directly with manufacturers. HHS and participating states would rigorously evaluate these demonstrations, which would provide states with new tools to control drug costs and tailor drug coverage decisions to state needs.

- Proposing in the President's FY2019 Budget to authorize the HHS Secretary to leverage Medicare Part D plans' negotiating power for certain drugs covered under Part B.

- Addressing price disparities in the international market. The Administration is updating a number of historical studies to analyze drug prices paid in countries that are a part of the Organisation for Economic Co-operation and Development (OECD).

\section{Creating Incentives to Lower List Prices}

The list price of a drug does not reflect the discounts or price concessions paid to a PBM, insurer, health plan, or government program. Obscuring these discounts can shift costs to consumers in commercial health plans and Medicare beneficiaries. Many incentives in the current system reward higher list prices, and HHS is interested in creating new incentives to reward drug manufacturers that lower list prices or do not increase them.

Since the beginning of the Trump Administration, HHS has taken a number of actions to create incentives to lower list prices.

These efforts include proposing in the President's FY2019 budget a 5-part plan to modernize the Medicare Part D program, a portion of which includes the exclusion of manufacturer discounts from the calculation of beneficiary out-ofpocket costs in the Medicare Part D coverage gap, and the establishment of a beneficiary out-of-pocket maximum in the Medicare Part D catastrophic phase to reduce outof-pocket spending for beneficiaries who spend the most on drugs. The changes in the catastrophic phase would shift more responsibility onto plans, creating incentives for plans to negotiate with manufacturers to lower prices for highcost drugs. We note that the 5-part plan is intended to be implemented together, as eliminating even one piece of the package significantly changes the proposal's impacts.

In addition, the President's FY2019 Budget proposes reforms to improve 340B Program integrity and 
ensure that the benefits derived from participation in the program are used to benefit patients, especially low-income and uninsured populations.

\section{Reducing Patient Out-of-Pocket Spending}

American patients have the right to know what their prescription drugs will really cost before they get to the pharmacy or get the drug. Too many people abandon their prescriptions at the pharmacy when they discover the price is too high, and too many patients are never informed of lower cost options.

Since the beginning of the Trump Administration, HHS has taken a number of steps to lower consumer out-of-pocket spending and improve transparency. These efforts include:

- Finalizing Medicare Outpatient Prospective Payment System (OPPS) rules to reduce beneficiary out-ofpocket spending for $340 \mathrm{~B}$ drugs administered in certain hospitals by an estimated $\$ 320$ million in 2018, which would equal $\$ 3.2$ billion when multiplied over ten years.

- Seeking information about changes in the Medicare Prescription Drug Program regulations for contract year 2019 that would increase transparency for people with Medicare prescription drug coverage. The proposed rule included a Request for Information soliciting comment on potential policy approaches for applying some manufacturer rebates and all pharmacy price concessions to the price of a drug at the point of sale.

- Finalizing changes to the Medicare Prescription Drug Program in the 2019 Part C and Part $D$ regulation allowing Medicare beneficiaries receiving low-income subsidies to access biosimilars at a lower cost.

- Proposing in the President's FY2019 Budget a 5-part plan to modernize the Medicare Part D program, a portion of which includes eliminating costsharing on generic drugs for low-income beneficiaries and requiring Medicare Part D plans to apply a substantial portion of rebates at the point of sale. We note that the 5-part plan is intended to be implemented together, as eliminating even one piece of the package significantly changes the proposal's impacts. We also note that in the months following this Part D proposed rule and the President's budget proposal that included this policy change explicitly, several major insurers and pharmacy benefit managers announced they would pass along a portion of rebates to individual members in their fully-insured populations or when otherwise requested by employers. 


\section{Responding to President Trump's Call to Action}

PRESIDENT TRUMP has called on the Administration to propose new strategies and take bold actions to improve competition and end the gaming of regulatory processes, support better negotiation of drug discounts through government insurance programs, create incentives for pharmaceutical companies to lower list prices, and reduce consumer out-of-pocket spending at the pharmacy and other care settings. HHS may undertake these and other actions, to the extent permitted by law, in response to President Trump's call to action.

\section{A. Improve Competition}

In response to President Trump's call to action, HHS may support improved competition by:

- Taking steps to prevent gaming of regulatory processes: FDA will issue guidance to address some of the ways in which manufacturers may seek to use shared system REMS to delay or block competition from generic products entering the market.

- Promoting innovation and competition for biologics. FDA will issue new policies to improve the availability, competitiveness, and adoption of biosimilars as affordable alternatives to branded biologics. FDA will also continue to educate clinicians, patients, and payors about biosimilar and interchangeable products as we seek to increase awareness about these important new treatments.

\section{B. Better Negotiation}

In response to President Trump's call to action, HHS may support better negotiation by:

- Directing Centers for Medicare \& Medicaid Services (CMS) to develop demonstration projects to test innovative ways to encourage value-based care and lower drug prices. These models should hold manufacturers accountable for outcomes, align with CMS priorities of value over volume and site-neutral payments, and provide Medicare providers, payers, and states with additional tools to manage spending for high-cost therapies.

- Allowing Part D plans to adjust formulary or benefit design during the benefit year if necessary to address a price 
increase for a sole source generic drug. Presently, Part D plans do not contract with generic drug manufacturers for the purchase of generic drugs, and generally are not permitted to change their formulary or benefit design without CMS approval in response to a price increase. This change could ensure Part $\mathrm{D}$ plans can respond to a price increase by the only manufacturer of a generic drug.

- Providing plans full flexibility to manage high-cost drugs that do not provide Part D plans with rebates or negotiated fixed prices, including in the protected classes. Presently, Part D plans are unable to negotiate lower prices for highcost drugs without competition. This change could allow Part D plans to use the tools available to private payers outside of the Medicare program to better negotiate for these drugs.

- Updating the methodology used to calculate Drug Plan Customer Service star ratings for plans that are appropriately managing utilization of high-cost drugs. Presently, if a Part D plan issues an adverse redetermination decision, the enrollee, the enrollee's representative or the enrollee's prescriber may appeal the decision to the Independent Review Entity (IRE). This process may discourage Part D plan sponsors from appropriately managing utilization of highcost drugs. This change could provide Part D plan sponsors with the ability to appropriately manage high-cost changes, while holding sponsors accountable primarily using other successful enforcement mechanisms.

- Evaluating options to allow high-cost drugs to be priced or covered differently based on their indication. Presently, Part D plans must cover and pay the same price for a drug regardless of the indication for which it was prescribed. This change could permit Part D plans to choose to cover or pay a different price for a drug, based on the indication.

- Sending the President a report identifying particular drugs or classes of drugs in Part B where there are savings to be gained by moving them to Part D.

- Taking steps to leverage the authority created by the Competitive Acquisition Program (CAP) for Part B Drugs \& Biologicals. This program will generally provide physicians a choice between obtaining these drugs from vendors selected through a competitive bidding process or directly purchasing these drugs and being paid under the current average sales price 
(ASP) methodology. The CAP, or a model building on CAP authority, may provide opportunities for Federal savings to the extent that aggregate bid prices are less than 106 percent of ASP, and provides opportunities for physicians who do not wish to bear the financial burdens and risk associated with being in the business of drug acquisition.

- Working in conjunction with the Department of Commerce, the U.S. Trade Representative, and the U.S. Intellectual Property Enforcement Coordinator to develop the knowledge base necessary to address the unfair disparity between the drug prices in America and other developed countries. The Trump Administration is committed to making the appropriate regulatory changes and seeking legislative solutions to put American patients first.

\section{Lowering List Prices}

In response to President Trump's call to action, HHS may:

- Call on the FDA to evaluate the inclusion of list prices in directto-consumer advertising.

- Direct CMS to make Medicare and Medicaid prices more transparent, hold drug makers accountable for their price increases, highlight drugs that have not taken price increases, and recognize when competition is working with an updated drug pricing dashboard. This tool will also provide patients, families, and caregivers with additional information to make informed decisions and predict their cost sharing.

- Develop proposals related to the Affordable Care Act's Maximum Rebate Amount provision, which limits manufacturer rebates on brand and generic drugs in the Medicaid program to $100 \%$ of the Average Manufacturer Price.

\section{Reduce Patient Out-of-Pocket Spending}

In response to President Trump's call for action, HHS may:

- Prohibit Part D plan contracts from preventing pharmacists from telling patients when they could pay less out-of-pocket by not using their insurance - also known as pharmacy gag clauses.

- Require Part D Plan sponsors to provide additional information about drug price increases and lower-cost alternatives in the Explanation of Benefits they currently provide their members. 


\section{Further Actions Under Review and Opportunities for Feedback}

BUILDING ON THE IDEAS already proposed, HHS is considering even bolder actions to bring down prices for patients and taxpayers. These include new measures to increase transparency; fix the incentives that may be increasing prices for patients; and reduce the costs of drug development. HHS is interested in public comments about how the department can take action to improve competition and end the gaming of regulatory processes, support better negotiation of drug discounts through government insurance programs, create incentives for pharmaceutical companies to lower list prices, and reduce consumer outof-pocket spending at the pharmacy and other care settings. HHS is also interested in public comments about the general structure and function of the pharmaceutical market, to inform these actions. Proposals described in this section are for administrative action, when within agency authority, and legislative proposals as necessary.

HHS is soliciting comments on these and other policies under active consideration.

\section{A. Increasing competition}

Underpricing or Cost-Shifting. Do HHS programs contain the correct incentives to obtain affordable prices on safe and effective drugs? Does the Best Price reporting requirement of the Medicaid Drug Rebate Program pose a barrier to price negotiation and certain value-based agreements in other markets, or otherwise shift costs to other markets? Are government programs causing underpricing of generic drugs, and thereby reducing long-term generic competition?

Affordable Care Act taxes and rebates. The Affordable Care Act imposed tens of billions of dollars in new taxes and costs on drugs sold in government programs through a new excise tax, an increase in the Medicaid drug rebate amounts, and an extension of these higher rebates to commercially-run Medicaid Managed Care Organizations. How have these changes impacted manufacturer list pricing practices? Are government programs being cross-subsidized by higher list prices and excess costs paid by individuals and employers in the commercial market? If cross-subsidization exists, are the taxes and artificially-depressed prices causing higher overall drug costs or other negative effects?

Access to reference product samples

Distribution restrictions. Certain prescription drugs are subject to 
limitations on distribution. Some of these distribution limitations are imposed by the manufacturer, while others may be imposed in connection with an FDA-mandated Risk Evaluation and Mitigation Strategy (REMS). Some manufacturers may be gaming these distribution limitations to prevent generic developers from accessing their drugs to conduct the tests that are legally required for a generic drug to be brought to market, thereby limiting opportunities for competition that could place downward pressure on drug prices. In some instances, for products that are subject to REMS that impact distribution, manufacturers continue to restrict access to generic developers even after the FDA issues a letter stating that it has favorably evaluated the developer's proposed safety protections for testing and would not consider the provision of drug samples to this developer for generic development to violate the applicable REMS. Should additional steps be taken to review existing REMS to determine whether distribution restrictions are appropriate? Are there terms that could be included in REMS, or provided in addition to REMS, that could expand access to products necessary for generic development? Are there other steps that could be taken to facilitate access to products that are under distribution limitations imposed by the manufacturer?

Samples for biosimilars and interchangeables. Like some ge-

\section{Some manufacturers} may be gaming distribution limitations to prevent generic developers from accessing their drugs.

neric drug developers, companies engaged in biosimilar and interchangeable product development may encounter difficulties obtaining sufficient samples of the reference product for testing. What actions should be considered to facilitate access to reference product samples by these companies?

\section{Biosimilar development, approval, education, and access}

Resources and tools from FDA: FDA prioritizes ongoing efforts to improve the efficiency of the biosimilar and interchangeable product development and approval process. For example, FDA is working to identify areas in which additional information resources or development tools may facilitate the development of high-quality biosimilar and inter- 
changeable products. What specific types of information resources or development tools would be most effective in reducing the development costs for biosimilar and interchangeable products?

Improving the Purple Book. In the Purple Book, FDA publishes information about biological products licensed under section 351 of the Public Health Service Act, including reference products, biosimilars, and interchangeable products. The Purple Book provides information about these products that is useful to prescribers, pharmacists, patients, and other stakeholders. FDA is committed to the timely publication of certain information about reference product exclusivity in the Purple Book. How could the Purple Book be more useful to health care professionals, patients, manufacturers, and other stakeholders? What additional information could be added to increase the utility of the Purple Book?

Educating providers and patients. Physician and patient confidence in biosimilar and interchangeable products is critical to the increased market acceptance of these products. FDA intends to build on the momentum of past education efforts, such as the launch of its Biosimilars Education and Outreach Campaign in 2017, by developing additional resources for health care professionals and patients. What types of information and educational resources on biosimilar and interchangeable products would be most useful to heath care professionals and patients to promote understanding of these products? What role could state pharmacy practice acts play in advancing the utilization of biosimilar products?

Interchangeability. How could the interchangeability of biosimilars be improved, and what effects would it have on the prescribing, dispensing, and coverage of biosimilar and interchangeable products?

\section{B. Better Negotiation}

The American pharmaceutical marketplace is built on innovation and competition. However, regulations governing how Medicare and Medicaid pay for prescription drugs have not kept pace with the availability of new types of drugs, particularly higher-cost curative therapies intended for use by fewer patients. Drug companies, commercial insurers, and states have proposed creative approaches to financing these new treatments, including indication-based pricing, outcomes-based contracts, long-term financing models, and others. Value-based transformation of our entire healthcare system is a top HHS priority. Improving price transparency is an important part of achieving this aim. What steps can be taken to improve price transparency in Medicare, Medicaid, and other forms of health coverage, so that consumers can seek value when choosing and using their benefits? 
Value-Based Arrangements and Price Reporting. What benefits would accrue to Medicare and Medicaid beneficiaries by allowing manufacturers to exclude from statutory price reporting programs discounts, rebates, or price guarantees included in value-based arrangements? How would excluding these approaches from Average Manufacturer Price (AMP) and Best Price (BP) calculations impact the Medicaid Drug Rebate program and supplemental rebate revenue? How would these exclusions affect Average Sales Price (ASP) and 340B Ceiling Prices? What benefits would accrue to Medicare and Medicaid beneficiaries by extending the time for manufacturers to report restatements of AMP and/ or $\mathrm{BP}$ reporting, as outlined in $42 \mathrm{CFR}$ $\$ 447.510$, to accommodate adjustments because of possible extended Value-based Purchasing (VBP) evaluation timeframes? Is there a timeframe CMS should consider that will allow manufacturers to restate AMP and $\mathrm{BP}$ without negative impact on state rebate revenue? What modifications could be made to the following regulatory definitions in the current Medicaid Drug Rebate Program that could facilitate the development of VBP arrangements: 1) bundled sale; 2) free good; 3) unit; or 4) best price? Would providing specific AMP/ $\mathrm{BP}$ exclusions for VBP pricing used for orphan drugs help manufacturers that cannot adopt a bundled sale approach? What regulatory changes would Medicaid Managed Care or- ganizations find helpful in negotiating VBP supplemental rebates with manufacturers? How would these changes affect Medicare or the $340 \mathrm{~B}$ program? Are there particular sections of the Social Security Act (e.g., the anti-kickback statute), or other statutes and regulations that can be revised to assist with manufacturers' and states' adoption of value-based arrangements?

Indication-based payments. Prescription drugs have varying degrees of effectiveness when used to treat different types of disease. Though drugs may be approved by the FDA to treat specific indications, or used off-label by prescribers to treat others, they are typically subject to the same price. Should Medicare or Medicaid pay the same price for a drug regardless of the diagnosis for which it is being used? How could indication-based pricing support value-based purchasing? What lessons could be learned from private health plans? Are there unintended consequences of current lowcost drugs increasing in price due to their identification as high value? How and by whom should value be determined?? Is there enough granularity in coding and reimbursement systems to support indication-based pricing? Are changes necessary to CMS's price reporting program definitions or how the FDA's National Drug Code numbers are used in CMS price reporting programs? Do physicians, pharmacists, and insurers have access to all the information they need to support indication-based payments? 
Long-term financing models. States and other payers typically establish budgets or premium rates for a given benefit year. As such, their budgets may be challenged when a new high-cost drug unexpectedly becomes available in the benefit year. Long-term financing models are being proposed to help states, insurers, and consumers pay for high-cost treatments by spreading payments over multiple years. Should the state, insurer, drug manufacturer, or other entity bear the risk of receiving future payments? How should Medicare or Medicaid account for the cost of disease averted by a curative therapy paid for by another payer? What regulations should CMS consider revising to allow manufacturers and states more flexibility to participate in novel value-based pricing arrangements? What effects would these solutions have on manufacturer development decisions? What current barriers limit the applicability of these arrangements in the private sector? What assurances would parties need to participate in more of these arrangements, particularly with regard to public programs?

Part B Competitive Acquisition Program. HHS has the authority to operate a Competitive Acquisition Program for Part B drugs. What changes would vendors and providers need to see relative to the 2007-2008 implementation of this program in order to successfully participate in the program? Has the marketplace evolved such that there would be more vendors capable of successfully participating in this program? Are there a sufficient number of providers interested in having a vendor selected through a competitive bidding process obtain these drugs on their behalf, and bear the financial risk and carrying costs? How could this program be implemented in a way that ensures a competitive market among multiple vendors? Is it necessary that the vendors also hold title to the drugs and provide a distribution channel or are there other ways they can provide value? What other approaches could lower Part B drug spending for patients of providers choosing not to participate, without restricting their access to care?

Part B to D. The President's Budget requested the authority to move some Medicare Part B drugs to Medicare Part D. Which drugs or classes of drugs would be good candidates for moving from Part B to Part $D$ ? How could this proposal be implemented to help reduce out-of-pocket costs for the $27 \%$ of beneficiaries who do not have Medicare prescription drug coverage, or those who have Medicare supplemental benefits in Part B? What additional information would inform how this proposal could be implemented and operated?

Part B drugs are reportedly available to OECD nations at lower prices than those paid by Medicare Part B providers. HHS is interested in receiving data describing the differ- 
ences between the list prices and net prices paid by Medicare Part B providers, and the prices paid for these same drugs by OECD nations. Though these national health systems may be demanding lower prices by restricting access or delaying entry, should Part B drugs sold by manufacturers offering lower prices to OECD nations be subject to negotiation by Part D plans? Would this lead to lower out-of-pocket costs on behalf of people with Medicare? How could this affect access to medicines for people with Medicare?

Fixing Global Freeloading. U.S. consumers and taxpayers generally pay more for brand drugs than do consumers and taxpayers in other OECD countries, which often have reimbursements set by their central government. In effect, other countries are not paying an appropriate share of the necessary research and development to bring innovative drugs to the market and are instead freeriding off U.S. consumers and taxpayers. What can be done to reduce the pricing disparity and spread the burden for incentivizing new drug development more equally between the U.S. and other developed countries? What policies should the U.S. government pursue in order to protect IP rights and address concerns around compulsory licensing in this area.

Site neutrality for physician-administered drugs. Currently under Medicare Part B and often in Medicaid, hospitals and physicians are reimbursed comparable

\section{"We want to look at negotiating for drugs in Medicare that have never been negotiated for." \\ - SECRETARY AZAR}

amounts for drugs they administer to patients, but the facility fees when drugs are administered at hospitals and hospital-owned outpatient departments are many times higher than the fees charged by physician offices. What effect would a site neutral payment policy for drug administration procedures have on the location of the practice of medicine? How would this change affect the organization of health care systems? How would this change affect competition for health care services, particularly for cancer care?

Site neutrality between inpatient and outpatient setting. Medicare payment rules pay for prescription drugs differently when provided during inpatient care (Part A) or administered by an outpatient physician (Part B). Beneficiaries also have different cost-sharing requirements in Part A and Part B. Some drugs can be administered in either the inpatient or outpatient setting, while 
"For high-cost products, the

\section{amount that}

Medicare pays

differs dramatically

based on the

site of service."

\section{- CMS ADMINISTRATOR}

SEEMA VERMA

others are currently limited to inpatient use because of safety concerns. Do the differences between Medicare's Part A and Part B drug payment policies create affordability and access challenges for beneficiaries? What policies should CMS consider to ensure inpatient and outpatient providers are neither underpaid nor overpaid for a drug, regardless of where it was administered? Which elements of the inpatient or outpatient setting lead to naturally differential payments, and why? If a drug can be used safely in the outpatient setting, and achieve the same outcomes at a lower cost, how should Medicare encourage the shift to outpatient settings? In what instances would inpatient administration actually be less costly?
Accuracy of national spending data. Are annual reports of health spending obscuring the true cost of prescription drugs? What is the value of better understanding the difference between gross and net drug prices? How could the Medicare Trustees Report, annual National Health Expenditure publications, Uniform Rate Review Template, and other publications more accurately collect and report gross and net drug spending in medical and pharmacy benefits? Should average Part D rebate amounts be reported separately for small molecule drugs, biologics, and high-cost drugs? What innovation is needed to maximize price transparency without disclosing proprietary information or data protected by confidentiality provisions?

\section{Create Incentives to Lower List Prices}

Government programs, commercial insurers, and individual consumers pay for drugs differently. The price paid at the pharmacy counter or reimbursed to a physician or hospital is the result of many different complex financial transactions between drug makers, distributors, insurers, Pharmacy Benefits Managers, pharmacies and others. Public programs are also subject to state and federal regulations governing what drugs are covered, who can be paid for them, and how much will be paid. Too often, these negotiations do not result in the lowest out-of-pocket 
costs for consumers, and may actually be causing higher list prices.

Fiduciary duty for Pharmacy Benefit Managers. Pharmacy Benefit Managers (PBMs) and benefits consultants help buyers (insurers, large employers) seek rebates intended to lower net drug prices, and help sellers (drug manufacturers) pay rebates to secure placement on health plan formularies. Most current PBM contracts may allow them to retain a percentage of the rebate collected and other administrative or service fees.

Do PBM rebates and fees based on the percentage of the list price create an incentive to favor higher list prices (and the potential for higher rebates) rather than lower prices? Do higher rebates encourage benefits consultants who represent payers to focus on high rebates instead of low net cost? Do payers manage formularies favoring benefit designs that yield higher rebates rather than lower net drug costs? How are beneficiaries negatively impacted by incentives across the benefits landscape (manufacturer, wholesaler, retailer, PBM, consultants, and insurers) that favor higher list prices? How can these incentives be reset to prioritize lower out-of-pocket costs for consumers, better adherence and improved outcomes for patients? What data would support or refute the premise described above?

Should PBMs be obligated to act solely in the interest of the entity for whom they are managing pharmaceutical benefits? Should PBMs be

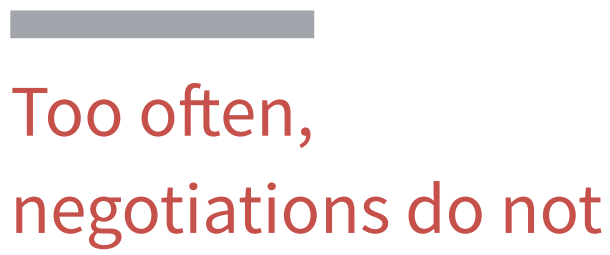

\section{result in the lowest out-of-pocket costs for consumers.}

forbidden from receiving any payment or remuneration from manufacturers, and should PBM contracts be forbidden from including rebates or fees calculated as a percentage of list prices? What effect would imposing this fiduciary duty on PBMs on behalf of the ultimate payer (i.e., consumers) have on PBMs' ability to negotiate drug prices? How could this affect manufacturer pricing behavior, insurance, and benefit design? What unintended consequences for beneficiary out-of-pocket spending and federal health program spending could result from these changes?

Reducing the impact of rebates. Increasingly higher rebates in federal health care programs may be causing higher list prices in public programs, and increasing the prices paid by consumers, employers, and commercial insurers. What should CMS consider doing to restrict or reduce the use of rebates? Should Medicare Part D prohibit the use of rebates in contracts between Part D plan sponsors and drug manufac- 
Increasingly

higher rebates

in federal health

care programs

may be causing

higher list prices.

turers, and require these contracts to be based only on a fixed price for a drug over the contract term? What incentives or regulatory changes (e.g., removing the discount safe harbor) could restrict the use of rebates and reduce the effect of rebates on list prices? How would this affect the behavior of drug manufacturers, PBMs, and insurers? How could it change formulary design, premium rates, or the overall structure of the Part D benefit?

Incentives to lower or not increase list prices. Should manufacturers of drugs that have increased their prices over a particular lookback period or have not provided a discount be allowed to be included in the protected classes? Should drugs for which a price increase has not been observed over a particular lookback period be treated differently when determining the exceptions criteria for protected class drugs? What should CMS consider doing, under current authorities, to create incentives for Part D drug manufacturers committing to a price over a particular lookback period? How long should the lookback period be?

The Healthcare Common Procedure Coding System (HCPCS) codes for new Part B drugs are not typically assigned until after they are commercially available. Should they be available immediately at launch for new drugs from manufacturers committing to a price over a particular lookback period? What should CMS consider doing, under current authorities, to create incentives for Part B drugs committing to a price over a particular lookback period? How long should the lookback period be?

How could these incentives affect the behavior of manufacturers and purchasers? What are the operational concerns to implementing them? Are there other incentives that could be created to reward manufacturers of drugs that have not taken a price increase during a particular lookback period?

Inflationary rebate limits. The Department is concerned that limiting manufacturer rebates on brand and generic drugs in the Medicaid program to $100 \%$ of calculated AMP allows for excessive price increases to be taken without manufacturers facing the full effect of the price inflationary penalty established by Congress. This policy, implemented as part of the ACA, may allow for run- 
away price increases and cost-shifting. When is this limitation a valid constraint upon the rebates manufacturers should pay? What impacts would removing the cap on the inflationary rebate have on list prices, price increases over time, and public and private payers?

Exclusion of certain payments, rebates, or discounts from the determination of Average Manufacturer Price and Best Price. The Department is concerned that excluding pharmacy benefit manager rebates from the determination of Best Price, implemented as part of the ACA, may allow for runaway price increases and cost-shifting. The Department is also interested in learning more about the effect of excluding payments received from, and rebates or discounts provided to Pharmacy Benefit Managers from the determination of Average Manufacturer Price.

What impacts would these changes have on list prices, price increases over time, and public and private payers? What data would support or refute the premise described above?

Copay discount cards. Does the use of manufacturer copay cards help lower consumer cost or actually drive increases in manufacturer list price? Does the use of copay cards incent manufacturers and PBMs to work together in driving up list prices by limiting the transparency of the true cost of the drug to the beneficiary? What data would support or refute the premise described above?
CMS regulations presently exclude manufacturer sponsored drug discount card programs from the determination of average manufacturer price and the determination of best price. What effect would eliminating this exclusion have on drug prices?

Would there be circumstances under which allowing beneficiaries of federal health care programs to utilize copay discount cards would advance public health benefits such as medication adherence, and outweigh the effects on list price and concerns about program integrity? What data would support or refute this?

\section{The 340B drug discount program}

The 340B Drug Pricing Program was established by Congress in 1992, and requires drug manufacturers participating in the Medicaid Drug Rebate Program to provide covered outpatient drugs to eligible health care providers-also known as covered entities - at reduced prices. Covered entities include certain qualifying hospitals and federal grantees identified in section $340 \mathrm{~B}$ of the Public Health Service Act (PHSA). The Health Resources and Services Administration (HRSA) administers and oversees the 340B Program, and the discounts provided may affect the prices paid for drugs used by Medicare beneficiaries, people with Medicaid, and those covered by commercial insurance.

Program growth. The $340 \mathrm{~B}$ program has grown significantly since 1992-not only in the num- 


\section{Does the use of} manufacturer

\section{copay cards help}

lower consumer

cost or actually drive increases

\section{in manufacturer \\ list price?}

ber of covered entities and contract pharmacies, but also in the amount of money saved by covered entities. HRSA estimates that covered entities saved approximately $\$ 6$ billion on approximately $\$ 12$ billion in discounted purchases in Calendar Year (CY) 2015 by participating in the 340B Program. ${ }^{\text {ii }}$ It is estimated that discounted drug purchases made by covered entities under the $340 \mathrm{~B}$ program totaled more than $\$ 16$ billion in 2016 - a more than 30 percent increase in 340B Program purchases in just one year.iii How has the growth of the $340 \mathrm{~B}$ drug discount program affected list prices? Has it caused cross-subsidization by increasing list prices applicable in the commercial sector? What impact has this had on insurers and payers, including Part D plans? Does the Group Purchasing Organization (GPO) exclusion, the establishment of the Prime Vendor Program, and the current inventory models for tracking $340 \mathrm{~B}$ drugs increase or decrease prices? What are the unintended consequences of this program? Would explicit general regulatory authority over all elements of the 340B Program materially affect the elements of the program affecting drug pricing?

Program Eligibility. Would changing the definition of "patient" or changing the requirements governing covered entities contracting with pharmacies or registering offsite outpatient facilities (i.e., child sites) help refocus the program toward its intended purpose?

Duplicate Discounts. The $340 \mathrm{~B}$ statute prohibits duplicate discounts. Manufacturers are not required to provide a discounted $340 \mathrm{~B}$ price and a Medicaid drug rebate for the same drug. Are the current mechanisms for identifying and preventing duplicate discounts effective? Are drug companies paying additional rebates over the

ii. 340B Drug Pricing Program Ceiling Price and Manufacturer Civil Monetary Penalties Regulation, 82 Fed. Reg. 1210, 1227 (Jan. 5, 2017).

iii. Aaron Vandervelde and Eleanor Blalock, Measuring the Relative Size of the 340B Program: 2012-2017, BERKELEY RESEARCH GROUP (July 2017), available at

https://www.thinkbrg.com/media/publication/928_Vandervelde_Measuring340Bsize-July-2017_WEB_FINAL.pdf. 
statutory $340 \mathrm{~B}$ discounts for drugs that have been dispensed to $340 \mathrm{~B}$ patients covered by commercial insurance? What is the impact on drug pricing given that private insurers oftentimes pay commercial rates for drugs purchased at $340 \mathrm{~B}$ discounts? Do insurers, pharmacy, PBM, or manufacturer contracts consider, address, or otherwise include language regarding drugs purchased at $340 \mathrm{~B}$ discounts? What should be considered to improve the management and the integrity of claims for drugs provided to $340 \mathrm{~B}$ patients in the overall insured market? What additional oversight or claims standards are necessary to prevent duplicate discounts in Medicaid and other programs?

\section{Reduce Patient}

\section{Out-of-Pocket Spending}

Part D end-of-year statement on drug price changes and rebates collected. Part D plans presently provide their members with an explanation of benefits, which includes information about the negotiated price for each of their dispensed prescriptions, and what the plan, member, and others paid. What additional information could be added about the rate of change in those prices over the course of the benefit year? Alternatively, could pharmacists be empowered to inform beneficiaries when prices for their drugs have changed? Would this information be best distributed by pharmacists at the point of sale, by Medicare as an

\section{Discounted drug purchases made under the 340B drug program totaled more than \$16 billion in 2016.}

annual report, or by the health plan on a more regular basis, or some combination of these approaches? Could CMS improve transparency for Medicare beneficiaries without violating the Part D program's confidentiality protections? What operational challenges or concerns about burden exist with this approach, and how could CMS measure compliance with this approach?

Federal preemption of contracted pharmacy gag clause laws. Right now, some contracts between health plans and pharmacies do not allow the pharmacy to inform a patient that the same drug or a competitor could be purchased at a lower price off-insurance. What purpose do these clauses serve other than to require beneficiaries pay higher out-of-pocket costs? What other communication barriers are in place between pharmacists and patients that could be impeding lower drug prices, out-of-pocket 
costs, and spending? Should pharmacists be required to ask patients in federal programs if they'd like information about lower-cost alternatives? What other strategies might be most effective in providing price information to consumers at the point of sale?

Inform Medicare beneficiaries with Medicare Part B and Part D about cost-sharing and lower-cost alternatives. Health plans and pharmacy benefit managers have found new ways to inform prescribers and pharmacists, when prescribing or dispensing a new prescription, about the formulary options, expected cost-sharing, and lower-cost alter- natives specific to individual patients. How could these tools reduce outof-pocket spending for people with Medicare? Is this technology present in all or most electronic prescribing or pharmacy dispensing systems? Should Medicare require the use of systems that support providing this information to patients? What existing systems, tools, or third-party applications could support the creation of these tools? Does the technology exist for this approach to be quickly and inexpensively implemented? Would this increase costs for the Medicare program? Does this create unreasonable burden for prescribers or pharmacists? 


\section{Endnotes}

1. Malkin, J. D., D. P. Goldman, and G. F. Joyce. "The Changing Face Of Pharmacy Benefit Design." Health Affairs 23, no. 1 (January/February 2004): 194-99.

2. "2016 Medicine Use and Spending in the U.S.," IQVIA

3. PL 111-148; Payment for covered outpatient drugs, § 42 U.S. Code § 1396r-8

4. "Medicaid Managed Care Enrollment Reports, 2009 \& 2010." Medicaid.gov. Accessed April 23, 2018. https://www.medicaid.gov/medicaid/managed-care/enrollment/index.html.

5. "Overview of the 340B Drug Pricing Program." MedPAC.gov. May 2015.

6. U.S. Congress. House. Energy \& Commerce Committee. Review of the $340 \mathrm{~B}$ Drug Pricing Program. 115th Cong. H. Rept.

7. Fein, Adam J. "The 340B Program Hits $\$ 16.2$ Billion in 2016; Now 5\% of U.S. Drug Market." Drug Channels. May 18, 2017. Accessed April 23, 2018. http://www.drugchannels.net/2017/05/ exclusive-340b-program-hits-162-billion.html.

8. Rémuzat, C., D. Urbinati, J. Roïz, A. Kornfeld, and M. Toumi. "Overview Of External Reference Pricing Systems In Europe." Journal of Market Access \& Health Policy17, no. 3 (September 15, 2015).

9. "External Price Referencing." WHO Collaborating Centre for Pharmaceutical Pricing and Reimbursement Policies. http://whocc.goeg.at/Glossary/PreferredTerms/External price referencing.

10. https://www.kff.org/report-section/ehbs-2017-section-9-prescription-drug-benefits/; https://www.cdc.gov/nchs/data/nhis/earlyrelease/ERHDHP Access 0617.pdf.

11. Shrank, William H., Niteesh K. Choudhry, Michael A. Fischer, Jerry Avorn, Mark Powell, Sebastian Schneeweiss, Joshua N. Liberman, Timothy Dollear, Troyen A. Brennan, and M. Alan Brookhart. "The Epidemiology of Prescriptions Abandoned at the Pharmacy." Annals of Internal Medicine 153, no. 10 (November 16, 2010): 633.

12. IQVIA proprietary data. 




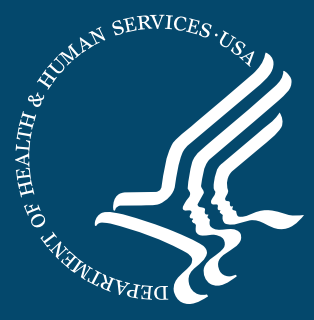

